\title{
Detection of Toxic Heavy Metal, Co(II) Trace via Voltammetry with Semiconductor Microelectrodes
}

\author{
Suw Young Ly', Chang Hyun Lee ${ }^{2}$ and Jae Mo Koo ${ }^{3}$ \\ 'Biosensor Research Institute, Seoul National University of Science and Technology, Seoul, Korea \\ ${ }^{2}$ Department of Integrated Environmental Systems, Pyeongtaek University, Pyeongtaek, Korea \\ ${ }^{3}$ Asia Pacific International School, Seoul, Korea
}

(Received November 3, 2016; Revised January 26, 2017; Accepted January 27, 2017)

\begin{abstract}
The cobalt (Co(II)) ion is a main component of alloys and considered to be carcinogenic, especially due to the carcinogenic and toxicological effects in the aquatic environment. The toxic trace of the Co(II) detection was conducted using the infrared photodiode electrode (IPDE) using a working electrode, via the cyclic and square-wave anodic stripping voltammetry. The results indicated a sensitive oxidation peak current of $\mathrm{Co}$ (II) on the IPDE. Under the optimal conditions, the common-type glassy carbon, the metal platinum, the carbon paste, and the carbon fiber microelectrode were compared with the IPDE in the electrolyte using the standard Co(II). The IPDE was found to be far superior to the others.
\end{abstract}

Key words: Infrared, Diode, Electrode, Anodic, Voltammetry, Trace cobalt (Co(II))

\section{INTRODUCTION}

In recent years, the intensive researches were directed towards the development of new organic materials for the organic light-emitting diodes (OLEDs), and substantial progress was achieved by using a variety of organic materials, meeting the chemical and physical requirements of the electroluminescent devices (1). Mid-infrared IR diode lasers have been widely used in the absorption experiments, particularly in molecular spectroscopy, the atmospheric measurements, and the kinetics (2), where the chelate-complexing agents of the $\mathrm{P}$ - or N-type semiconductor are the electron donors and acceptors. Therefore, the quasi-Fermi-level semiconductor can be used for the voltammetric electrode sensors. It has also been used for the trace gas analysis (3), the methane detection $(4,5)$, the potassium $(6)$, the atmospheric $\mathrm{CH}_{4}, \mathrm{H}_{2} \mathrm{O}$ (7), and the copper and cadmium ions (8). In this study, the photodiode was used as a working electrode, with promising results. Moreover, as cobalt ion shows hardness, strength, and abrasion resistance at the elevated tempera-

Correspondence to: Suw Young Ly, Biosensor Research Institute, Seoul National University of Science and Technology, 172, gongreung 2-dong, Nowon-gu, Seoul 01811, Korea E-mail: suwyoung@snut.ac.kr

This is an Open-Access article distributed under the terms of the Creative Commons Attribution Non-Commercial License (http:// creativecommons.org/licenses/by-nc/3.0) which permits unrestricted non-commercial use, distribution, and reproduction in any medium, provided the original work is properly cited. tures, the automotive, aerospace, and arms industries are the prospective areas for its application. Co(II) is mostly used as a main component of the alloys and considered as a carcinogenic agent, which can be a possible cause of lung cancer (9). The possible human carcinogen (10) and the toxicological effects in the aquatic environment (11), due to its toxicity and utility, are important for the detection of cobalt. Thus, several methods of the cobalt detection have been developed, such as the precipitation method, the stoppedflow techniques, the CCD detection (12), the FT-IR studies (13), the resonance-ionization mass spectrometry (14), the ESI mass spectrometry (15), and the gas chromatography with the mass spectrometric detection (GCMS) (16). These methods are too complicated and time-consuming, whereas the voltammetric methods are simple and less time-consuming. The voltammetric methods have also been developed, such as those involving the use of the plated-lead-film electrode (17), the mercury film electrode (18), the bismuth film microelectrode (19), the platinum disc electrode (20), and the modified electrode with the hybrid hexacyanoferrates (21). These electrodes can detect the low cobalt concentrations. In this study, the IPDE was found to be more sensitive in terms of the cobalt detection and other toxic heavy metals $(22,23)$.

\section{MATERIALS AND METHODS}

Systems, reagents, and the electrode preparation. The IPDE was prepared with the SPI5342-H from the AUK 
Semiconductor. A sensing range of $430 \mathrm{~nm} \sim 1,050 \mathrm{~nm}$ with the wavelength of $950 \mathrm{~nm}$ and with the packing sizes of $4.8 \sim 5.5 \mathrm{~mm}$ was used as the audio control circuits. Regarding the photo diode, the forward and backward electrodes responded to the same results of the anodic or cathodic reactions. Electrochemical instruments were used with the new system of Bioelectronics-1, which was first constructed at the authors' institute.

Voltammetric property. Fig. 1A shows the cyclic voltammetry (CV) effect in the blank electrolyte and the 300$\mathrm{mg} / \mathrm{L}$ cobalt addition. With regard to the blank solution, the peak current did not have any signal. After the 300-mg/L cobalt was spiked, the peak current of $1.756 \times 10^{-4} \mathrm{~A}$ was obtained with the $-0.2 \mathrm{~V}$ oxidation and the $-0.45 \mathrm{~V}$ reduction peak. Fig. 1B shows the four types of the common electrodes which were compared with the IPDE, the glassy carbon, the metal platinum, the carbon paste electrode, and the carbon fiber micro electrodes. Here, the peak current of the IPDE was highest and was sharpest among the elec- trodes. For this reason, the IPDE was chosen as a working electrode. Fig. 1C shows the concentration effects of the $0.5 \sim 10 \mathrm{mg} / \mathrm{L} \mathrm{Co}(\mathrm{II})$ variation. The peak current increased from 0.1 to $0.3619 \times 10^{-3} \mathrm{~A}$, which can be used in the optimal parameters.

The square-wave optimized conditions. Fig. 2A shows the effects of the electrolyte $\mathrm{pH}$ variation on the peak current. From pHs of 2.92 to 10.98 the strengths were examined using the $0.1 \mathrm{M} \mathrm{HCl}$ and $0.1 \mathrm{M} \mathrm{NaOH}$ titrations. The peak current decreased from 3.042 to $1.556 \times 10^{-3} \mathrm{~A}$ within the $2.97 \mathrm{pH} \sim 8.36 \mathrm{pH}$ range, and it slightly increased to $1.566 \times 10^{-3} \mathrm{~A}$ at $9.07 \mathrm{pH}$. It decreased again from 1.76 to 1.575 within the $10.1 \sim 10.98 \mathrm{pH}$ range. As the maximum current was obtained at $2.97 \mathrm{pH}$, it was chosen as an optimum condition. Under the acidic conditions, the accumulation potentials were searched. Fig. $2 \mathrm{~B}$ shows the results from the -100 to $-800 \mathrm{~V}$ potential variation. The peak current decreased from 0.768 to $0.7389 \times 10^{-3} \mathrm{~A}$ within the $-100 \mathrm{~V} \sim-200 \mathrm{~V}$, and increased from 0.7876 to $0.8313 \times$
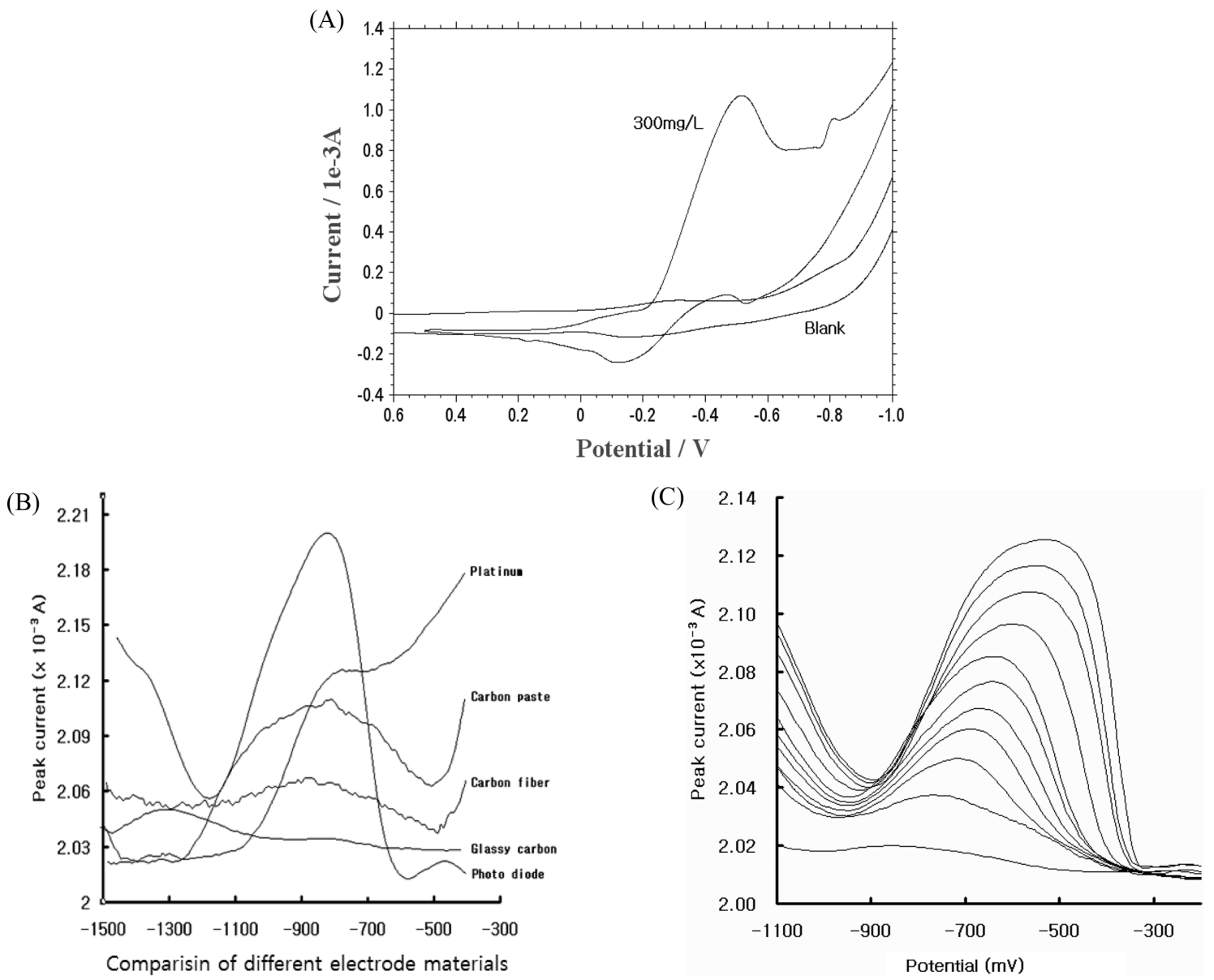

Fig. 1. (A) CV voltammograms of electrolyte blank and 300-mg/L Co(II) add, $-1.0 \mathrm{~V}$ initial potential, $0.8 \mathrm{~V}$ switching potential, $500 \mathrm{mV} / \mathrm{S}$ scan rate. (B) Sensor property of IPDE, glassy carbon, metal platinum, carbon paste, and carbon fiber micro electrode. (C) Stripping voltammetric concentration effects of 0.5-, 1-, 2-, 3-, 4-, 5-, 6-, 7-, 8-, 9- and 10-mg/L Co(II) add using IPDE with optimum conditions. 

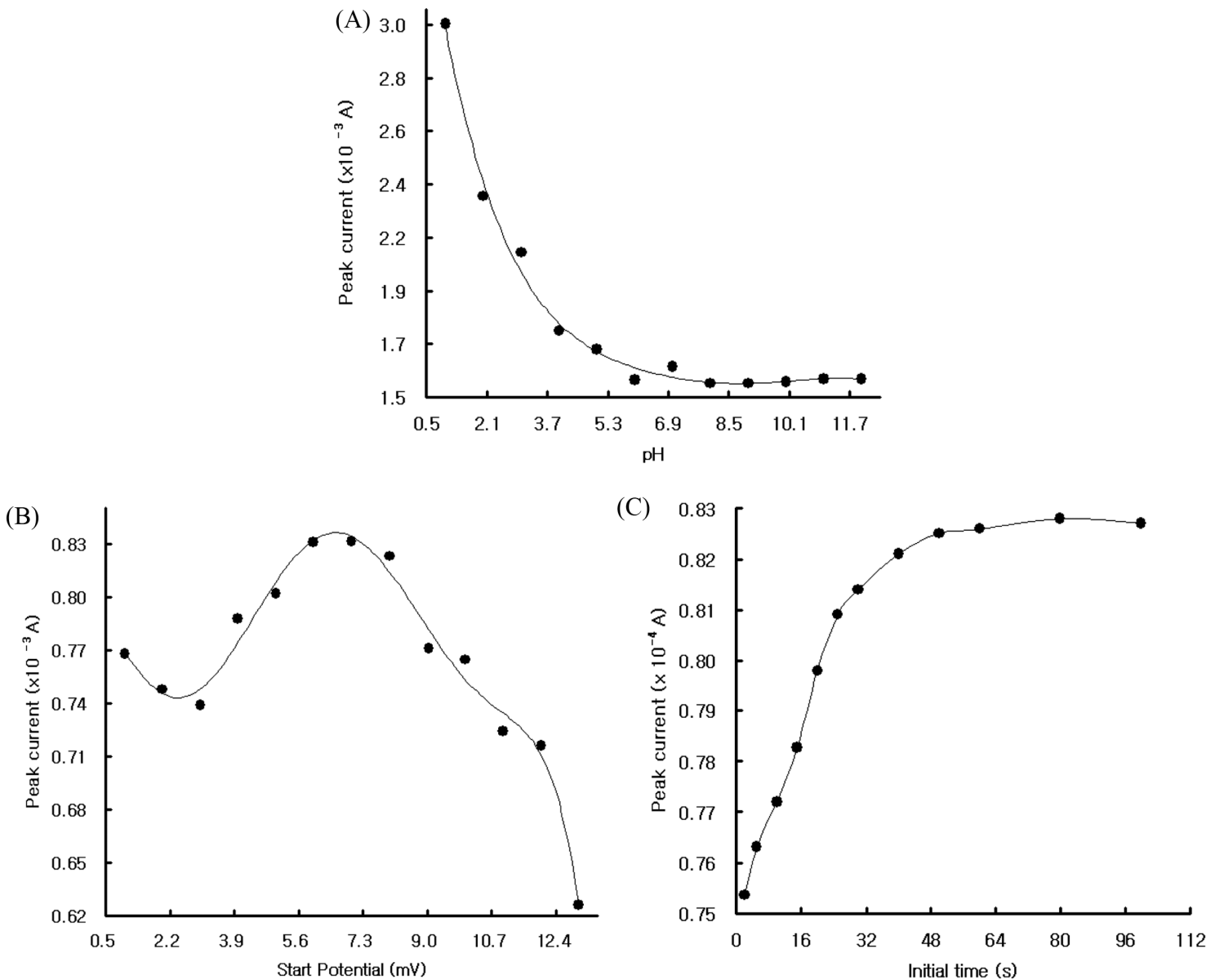

Fig. 2. (A) The square wave stripping voltammetry (SW) $\mathrm{pH}$ variation of $2.92,3.72,4.31,4.6,5.24,6.07,6.88,7.69,8.36,9.07,10.1$, and 10.98 strength. (B) Variation of $100,-150,-200,-250,-300,-350,-400,-450,-500,-550,-600,-700$, and -800 V accumulation potential. (C) The 1, 5, 10, 15, 20, 25, 30, 40, 50, 60, 80, and $100 \mathrm{sec}$ SW accumulation time variation.

$10^{-3} \mathrm{~A}$ within the $-250 \mathrm{~V} \sim-400 \mathrm{~V}$. At $-400 \mathrm{~V}$, the maximum current was obtained. Fig. 2C shows the stripping time effects from the $0 \mathrm{sec}$ to $100 \mathrm{sec}$ variation. The peak current increased from 0.7536 to $0.828 \times 10^{-4} \mathrm{~A}$ within the $2 \mathrm{sec} \sim 80 \mathrm{sec}$ range and decreased slightly to $0.827 \times 10^{-4} \mathrm{~A}$ at $100 \mathrm{sec}$. The maximum current was obtained at $80 \mathrm{sec}$, and the optimal conditions, interferences, statistics, and applications were examined.

\section{RESULTS}

Statistics, working ranges and the applications. The analytical interference effects were studied by adding several other ions into the medium containing the $40-\mathrm{mg} / \mathrm{L}$ $\mathrm{Co}$ (II) analysis. The existence of the $40-\mathrm{mg} / \mathrm{L} \mathrm{Fe}(\mathrm{II}), \mathrm{Cd}$, $\mathrm{Hg}, \mathrm{Zn}(\mathrm{II}), \mathrm{Cu}(\mathrm{II}), \mathrm{Cr}(\mathrm{III})$, and $\mathrm{Ni}(\mathrm{II})$ resulted in -74.630 , $-2.121,9.317,-5.352,-14.241,7.937$, and the $13.122 \%$ changes, respectively (data not shown). On the other hand, Fig. 3A, showing the presence of a three-fold excess of $\mathrm{Fe}(\mathrm{II}), \mathrm{Cd}(\mathrm{II}), \mathrm{Hg}(\mathrm{II}), \mathrm{Zn}(\mathrm{II}), \mathrm{Cu}(\mathrm{II}), \mathrm{Cr}(\mathrm{III})$, and $\mathrm{Ni}(\mathrm{II})$ resulted in the $100,405.161,30.204,-80.088,157.389$, $-6.603,-59.221$, and $1.005 \%$ changes, respectively. The interference effects were also calibrated using the standard addition methods. Under these conditions, Fig. 3B, shown results for repeated statistic detection peak currents, only 42.0 15.0 $\mu \mathrm{A}$ width appeared. Fig. $3 \mathrm{C}$ shows the analytical working range of the $0.5 \sim 18 \mathrm{mg} / \mathrm{L} \mathrm{Co}$ (II) variations. Three ranges were obtained: The result of the linear equation of $\mathrm{y}=0.030 \mathrm{x}+0.094$, with $\mathrm{R}^{2}=0.0994$. Their slope sensitivities were sharp. The results show that the IPDE can detect cobalt in low concentrations and can be applied to the fields where the cobalt detection is needed.

The analytical applications were performed on the pharmaceutical-company waste and on the waste of a sewage disposal plant near the city, using the standard addition method based on the optimum conditions. Fig. 4A shows the pharmaceutical waste. The first is the electrolyte blank, and the $1 \mathrm{~mL}$ non-treated waste spike, and the peak current of 39.1 were obtained. After that, the $2 \mathrm{mg} / \mathrm{L} \mathrm{Co}$ (II) standards, the $4 \mathrm{mg} / \mathrm{L} \mathrm{Co(II)} \mathrm{standards,} \mathrm{and} \mathrm{the} 6 \mathrm{mg} / \mathrm{L} \mathrm{Co(II)}$ 
(A)

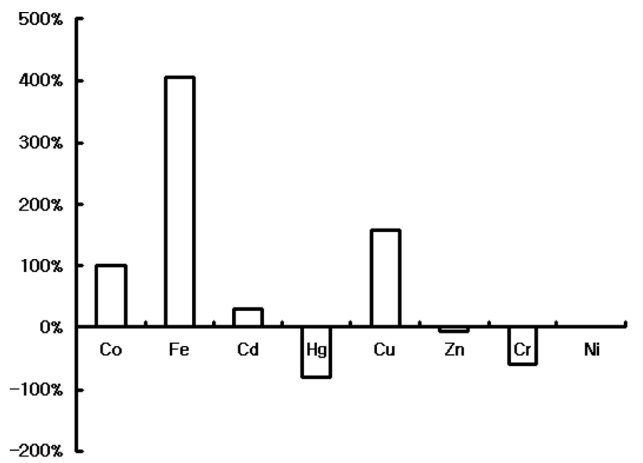

(B)

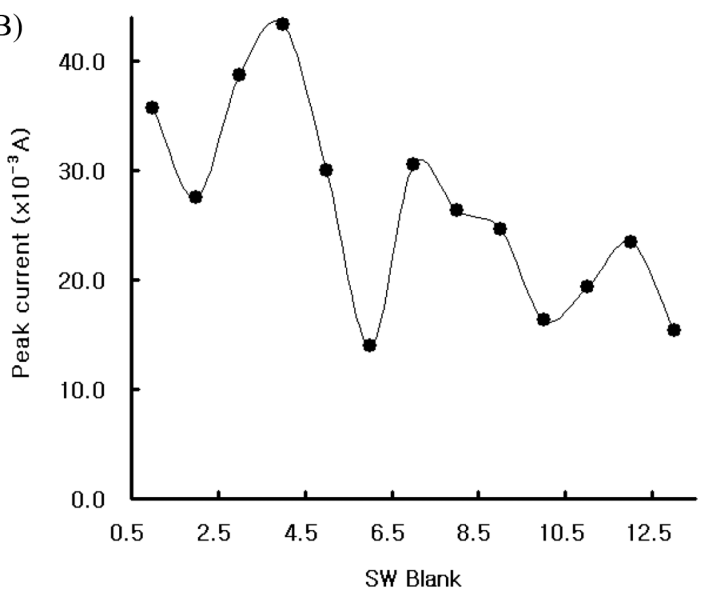

(C)

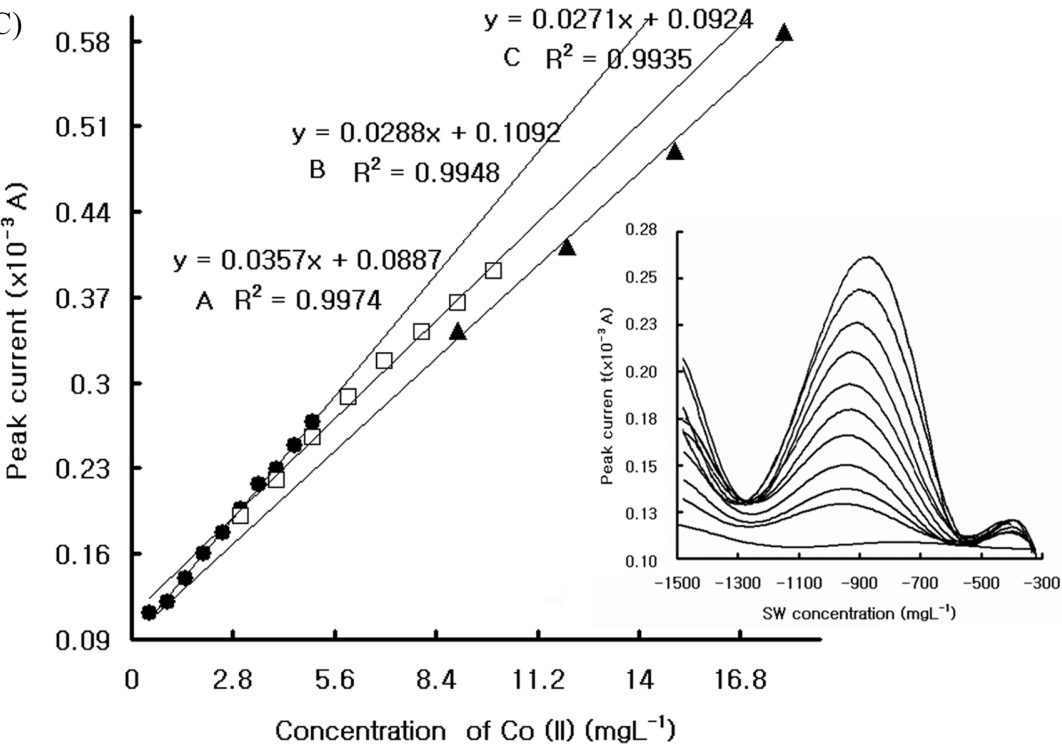

Fig. 3. (A) The results of the interference analogy metal ions. (B) Statistics. (C) The SW concentration effects based on the optimum conditions, with $80 \mathrm{sec}$ accumulation time.
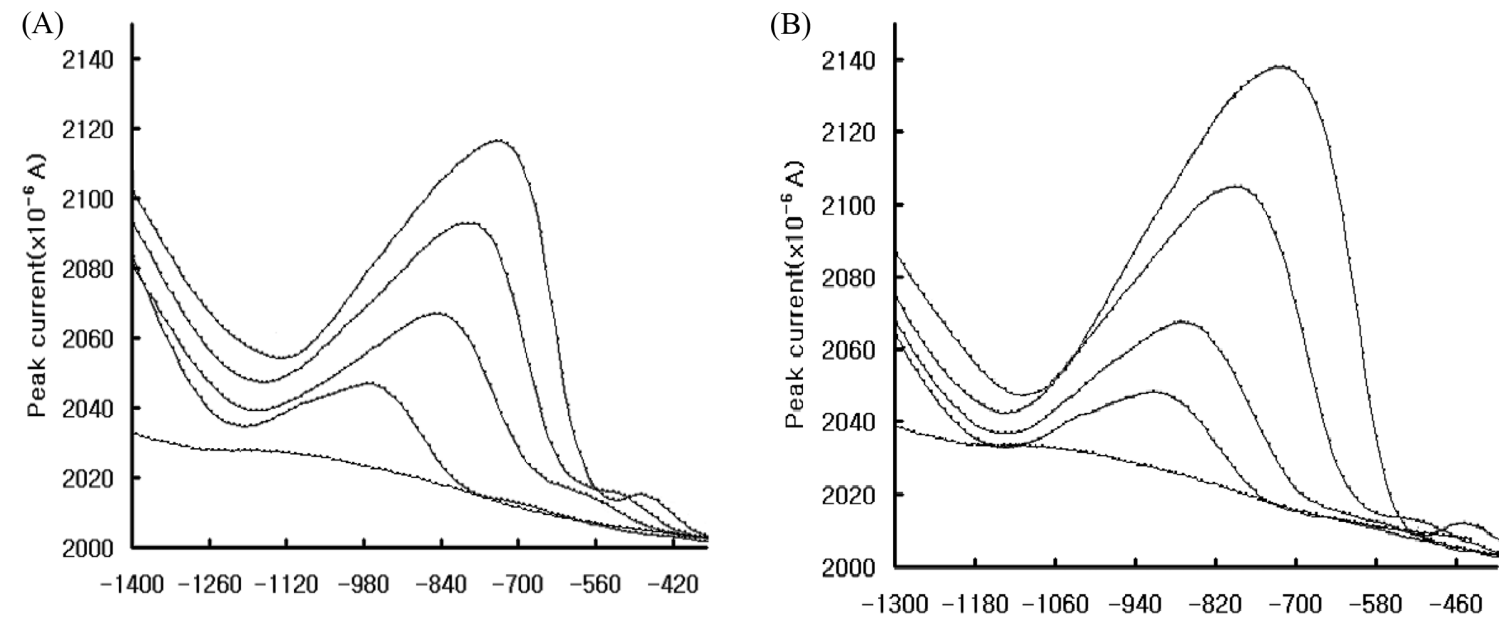

Fig. 4. (A) Analytical application to pharmaceutical-company waste using stripping voltammetry. (B) Application to the waste of a sewage disposal plant near the city, using stripping optimum conditions with $80 \mathrm{sec}$ accumulation time. 
standards were spiked, in that order. They increased from 45.87 to 70.4 . The result's equation was $y=8.259 x+29.23$ with $\mathrm{R}^{2}=0.985$ (not shown here). Fig. 4B shows the application to the waste of a sewage disposal plant near the city, where $1-\mathrm{mL}$ waste was spiked and the peak current of 33.5 was obtained. Then, the $2 \mathrm{mg} / \mathrm{L} \mathrm{Co}$ (II) standard, the $4 \mathrm{mg} / \mathrm{L}$ $\mathrm{Co}(\mathrm{II})$ standard, and the $6 \mathrm{mg} / \mathrm{L} \mathrm{Co}$ (II) standard were spiked, and the 45, 54.32, and 59.39 peak currents were obtained. The peak current increased continuously. These results mean that cobalt exists in the wastes of the pharmaceutical companies and the sewage disposal plants. The square-wave stripping voltammetry method and the IPDE electrode were used to detect the low cobalt concentrations.

\section{DISCUSSION}

The analytical optimal conditions were examined, and the results were obtained. The IPDE electrode showed a high sensitivity for the detection of cobalt ions. In this condition, the common-type probe was compared using the IPDE in the same electrolyte with the $10 \mathrm{mg} / \mathrm{L} \mathrm{Co}$ (II) standard addition, using the stripping optimal parameters for the $30 \mathrm{sec}$ accumulation. Each peak obtained the platinum $\left(0.03 \times 10^{-3} \mathrm{~A}\right)$, the carbon paste $\left(0.07 \times 10^{-3} \mathrm{~A}\right)$, the carbon fiber $(0.04 \times$ $\left.10^{-3} \mathrm{~A}\right)$, the grassy carbon $\left(0.01 \times 10^{-3} \mathrm{~A}\right)$, and the IPDE $\left(0.03 \times 10^{-3} \mathrm{~A}\right)$. The IPDE is ten times more sensitive than the other probes such as the platinum, the carbon paste, the carbon fiber and the grassy carbon. Which of final working range were obtained of the $0.5 \sim 5.6 \mathrm{mg} / \mathrm{L}, 2.9 \sim 10.2 \mathrm{mg} / \mathrm{L}$, $8.7 \sim 18.5 \mathrm{mg} / \mathrm{L} \mathrm{Co}(\mathrm{II})$ variations, moreover working equations for $\mathrm{Y}=0.0357 \mathrm{X}+0.0887, \mathrm{R}^{2}=0.9974, \mathrm{y}=0.0288 \mathrm{X}+$ $0.1092, R^{2}=0.9948$, and $y=0.0271 X+0.0924, R^{2}=0.9935$ obtained. Under the optimum conditions, the analytical detection limit was attained at $52 \mu \mathrm{g} / \mathrm{L} \mathrm{Co}$ (II). The result was applied to the soil waste and the waste of a sewage disposal plant near the city. The current IPDE results can be useful for the analytical applications to the pharmaceuticalcompany wastes, the wastes of the sewage disposal plants and can also be used in the other fields that require the detection of cobalt ions.

\section{REFERENCES}

1. Posch, P., Fink, R., Thelakkat, M. and Schmidt, H.W. (1998) A comparison of hole blocking/electron transport polymers in organic LEDs. Acta Polym., 49, 487-494.

2. Qian, H.-b., Turton, D., Seakins, P.W. and Pilling, M.J. (2000) Dynamic frequency stabilization of infrared diode laser for kinetic studies. Chem. Phys. Lett., 322, 57-64.

3. Gagliardi, G. and Gianfrani, L. (2002) Trace-gas analysis using diode lasers in the near-IR and long-path techniques. Opt. Laser Eng., 37, 509-520.

4. Zeninari, V., Parvitte, B., Courtois, D., Kapitanov, V.A. and Ponomarev, Yu.N. (2003) Methane detection on the sub-ppm level with a near-infrared diode laser photoacoustic sensor.
Infrared Phys. Technol., 44, 253-261.

5. Yamamoto, K. and Yoshida, N. (2002) High-precision isotopic ratio measurement system for methane $\left({ }^{12} \mathrm{CH}_{3} \mathrm{D} /{ }^{12} \mathrm{CH}_{4},{ }^{13} \mathrm{CH}_{4} /\right.$ ${ }^{12} \mathrm{CH}_{4}$ ) by using near-infrared diode laser absorption spectroscopy. Spectrochim. Acta A Mol. Biomol. Spectrosc., 58, 26992707.

6. Schlosser, E., Fernholz, T., Teichert, H. and Ebert, V. (2002) In situ detection of potassium atoms in high-temperature coalcombustion systems using near-infrared-diode lasers. Spectrochim. Acta A Mol. Biomol. Spectrosc., 58, 2347-2359.

7. Durry, G. (2001) Balloon-borne near-infrared diode laser spectroscopy for in situ measurements of atmospheric $\mathrm{CH}_{4}$ and $\mathrm{H}_{2} \mathrm{O}$. Spectrochim. Acta A Mol. Biomol. Spectrosc., 57, 18551863.

8. Ly, S.Y. and Kim, J.K. (2009) Simultaneous real-time assay of copper and cadmium ions by infrared photo diode electrode implanted in the muscle of live fish. J. Biochem. Mol. Toxicol., 23, 256-262.

9. Lison, D., De Boeck, M., Verougstraete, V. and KirschVolders, M. (2001) Update on the genotoxicity and carcinogenicity of cobalt compounds. Occup. Environ. Med., 58, 619625.

10. IARC Working Group on the Evaluation of Carcinogenic Risks to Humans (2006) Cobalt in hard metals and cobalt sulfate, gallium arsenide, indium phosphide and vanadium pentoxide. IARC Monogr. Eval. Carcinog. Risks Hum., 86, 1-294.

11. Suganthi, P., Soundarya, N., Stalin, A. and Nedunchezhiyan, S. (2015) Toxicological effect of cobalt chloride on freshwater fish Oreochromis mossambicus. Int. J. Appl. Res., 1, 331340.

12. Pettas, I.A. and Karayannis, M.I. (2003) Application of twoway decomposition methods in the simultaneous determination of cobalt, nickel and iron by coupling stopped-flow techniques and CCD detection. Anal. Chim. Acta, 491, 219-229.

13. Pakuła, M., Świątkowskib, A., Walczykc, M. and Biniakc, S. (2005) Voltammetric and FT-IR studies of modified activated carbon systems with phenol, 4-chlorophenol or 1,4-benzoquinone adsorbed from aqueous electrolyte solutions. Colloids Surf. A Physicochem. Eng. Asp., 260, 145-155.

14. Song, K., Cha, H., Park, S.-H. and Lee, Y.-I. (2003) Determination of trace cobalt in fruit samples by resonance ionization mass spectrometry. Microchem. J., 75, 87-96.

15. Mbaiwa, F.F. and Becker, C.A.L. (2006) Diphosphine substitution in pentakis (arylisocyanide) cobalt(I) complexes; 31P NMR, cyclic voltammetric and ESI mass spectrometry studies. Inorganica Chim. Acta, 359, 1041-1049.

16. Wasinski, F.A. and Andersson, J.T. (2007) Qualitative analysis of phenols and alcohols in complex samples after derivatization to esters of ferrocene carboxylic acid by gas chromatography with mass spectrometric detection. J. Chromatogr. A, 1157, 376-385.

17. Korolczuk, M., Tyszczuk, K. and Grabarczyk, M. (2005) Adsorptive stripping voltammetry of nickel and cobalt at in situ plated lead film electrode. Electrochem. Commun., 7, 1185-1189.

18. Farghaly, O.A. (2003) Direct and simultaneous voltammetric analysis of heavy metals in tap water samples at Assiut city: an approach to improve the analysis time for nickel and cobalt determination at mercury film electrode. Microchem. J., 75, 
119-131.

19. Hutton, E.A., Ogorevc, B., Hocevar, S.B. and Smyth, M.R. (2006) Bismuth film microelectrode for direct voltammetric measurement of trace cobalt and nickel in some simulated and real body fluid samples. Anal. Chim. Acta, 557, 57-63.

20. De Strycker, J., Westbroek, P. and Temmerman, E. (2002) Electrochemical behaviour and detection of $\mathrm{Co}(\mathrm{II})$ in molten glass by cyclic and square wave voltammetry. Electrochem. Commun., 4, 41-46.

21. Cui, X., Hong, L. and Lin, X. (2002) Electrochemical preparation, characterization and application of electrodes modified with hybrid hexacyanoferrates of copper and cobalt. J. Electroanal. Chem., 526, 115-124.

22. Yang, M.-J., Kim, J.-S., Yang, Y.-S., Cho, J.-W., Choi, S.-B., Chung, Y.-H., Kim, Y.-B., Cho, K.-H., Lim, C.-W., Kim, C.-Y. and Song, C.-W. (2008) Pulmonary toxicity and recovery from inhalation of manual metal arc stainless steel welding fumes in rats. Toxicol. Res., 24, 119-127.

23. Ryu, H.-W., Lee, D.H., Won, H.-R., Kim, K.H., Seong, Y.J. and Kwn, S.H. (2015) Influence of toxicologically relevant metals on human epigenetic regulation. Toxicol. Res., 31, 1-9. 